\title{
A static model for estimating energy content of compound feeds in a dynamic feed evaluation system
}

\author{
C. Álvarez, ${ }^{1,2 *} \odot$ N. I. Nielsen, ${ }^{3} \odot$ M. R. Weisbjerg, ${ }^{4} \odot$ H. Volden, ${ }^{1,2}{ }^{\oplus} \odot$ and E. Prestløkken ${ }^{1} \odot$ \\ ${ }^{1}$ Department of Animal and Aquaculture Sciences, Norwegian University of Life Sciences, 1432 Ås, Norway \\ ${ }^{2}$ TINE SA, 1432 Ås, Norway \\ ${ }^{3}$ SEGES, Danish Agriculture and Food Council, 8200 Aarhus, Denmark \\ ${ }^{4}$ Department of Animal Science, AU Foulum, Aarhus University, 8830 Tjele, Denmark
}

\section{ABSTRACT}

The objective of the study was to develop a static empirical model for the estimation of net energy content of compound feeds in a dynamic feeding system using net energy for lactation at $20 \mathrm{~kg}$ of dry matter intake/d (NEL20) values calculated by the Nordic Feed Evaluation System (NorFor) model. In the NorFor system, NEL20 is a standardized value used to describe net energy content of feeds. The static model would allow prediction of the net energy value of compound feeds without access to the input data needed for the dynamic models. Our hypothesis was that NEL20 values of compound feeds can be predicted using organic matter digestibility (in vitro) and chemical components of the compound feeds as input variables. For this, 75 compound feeds and their 108 associated ingredients were collected across Scandinavia for model development. The proposed best model for prediction of compound feed NEL20 included crude fat, neutral detergent fiber, digestible organic matter measured in vitro, and crude protein (urea corrected) as independent variables. Lack of additivity of chemical components between values analyzed directly in the compound feed and values calculated by the weighted sum of ingredients was detected as the main source of error in the model, emphasizing the importance of accurate chemical analysis and sampling practices. Results from practical use of the model show that it may be a valuable tool that could be used by several actors in the feeding sector using the NorFor system. Feed manufacturers could use it to monitor the net energy content in their final product, and farmers could use it to check the net energy content of the purchased compound feed. However, validation of this model against an independent set of samples is lacking in this study and its prediction performance should be further evaluated. The model will need recalibration

Received October 21, 2020.

Accepted March 22, 2021.

*Corresponding author: clementina.alvarez@tine.no if the feed parameters used in the dynamic model for the estimation of reference values change, as this would not be reflected in the predicted values of the created model.

Key words: energy estimation, additivity, in vitro digestibility, concentrate ingredient, dairy cow

\section{INTRODUCTION}

In recent decades, several dynamic mechanistic models have been developed for feed and ration evaluation, such as the Cornell Net Carbohydrate and Protein System (Tylutki et al., 2008), the Nordic Feed Evaluation System (NorFor; Volden, 2011), and the INRA Feeding System for Ruminants (Sauvant et al., 2018). Although these models incorporate time as a variable with detailed biological interactions, they have limitations in practice, such as a lack of available data or poor data quality to use as input for the model (Tedeschi et al., 2005).

Net energy content estimation for compound feeds in the NorFor system is a good example of a dynamic model. The NorFor system does not have a fixed net energy of lactation value for feedstuffs because dietary interactions between feedstuffs, such as nutrient degradation and passage rate with feed intake level, are considered. However, for purchasing decisions and feedstuff ranking, a comparison of the energy contents of feedstuffs is essential; thus, standard net energy values for individual feedstuffs were formulated in NorFor (Åkerlind and Volden, 2011). The net energy of lactation at $20 \mathrm{~kg}$ of DMI/d (NEL20) is the most used standard energy value. The NEL20 values $(\mathrm{MJ} / \mathrm{kg}$ of DM) are created for all feedstuffs, considering the same fixed input parameters, such as animal characteristics (600 kg of weight, $20 \mathrm{~kg}$ of DMI/d), $50 \%$ concentrate proportion in the diet, and passage rates for $\mathrm{CP}$, starch, and NDF, among others. Other variables are feedstuff specific, such as chemical composition, degradation rates, and indigestible fractions. For raw materials (e.g., grains and by-products), in sacco characteristics, 
such as degradation rates and indigestible fractions, are taken from the NorFor Feed Table (NorFor, 2020) based on Nordic databases and in situ characteristics. These input values are unavailable for commercial compound feeds, so NEL20 is calculated by the weighted sum of the ingredients (Akkerlind and Volden, 2011), making it reliant on ingredient composition. However, in the European Union (EU), declaration of the ingredient proportion of compound feeds is not mandatory. Hence, to have an accurate diet formulation, an alternative method for estimating the net energy of compound feeds (NEL20 in NorFor), independent from ingredient composition, is required.

Several feeding systems have static empirical equations for the energy prediction of compound feeds based on OM digestibility (OMD) in vitro and chemical composition as explanatory variables; see, for example, the INRA system, the English Feed Into Milk system (Thomas, 2004), the German system (GfE, 2009), and the Danish system (Weisbjerg and Hvelplund, 1993). The objective of our study was to develop a static empirical model for the estimation of net energy content of compound feeds in a dynamic feeding system using NEL20 values calculated by the NorFor model. A successful static model would allow accurate prediction of the energy value of compound feeds without access to the input data needed for the dynamic models. Our hypothesis was that NEL20 values of compound feeds can be predicted using OMD (in vitro) and chemical components of the compound feeds as input variables.

\section{MATERIALS AND METHODS}

\section{Samples}

We collected a total of 75 compound feed samples together with their associated ingredients (108 ingredient samples) over 2 yr from 6 feed companies in Denmark, Sweden, and Norway (2 companies from each country). Collected ingredients were sampled from the batch from which the compound feed samples were produced, and the exact recipe for compound feeds samples was provided. To ensure variation between years, we gathered samples from different feed companies and different feed mills from the same company (with different ingredient sources) over a period of $2 \mathrm{yr}$.

Compounds and ingredient samples included at $2 \%$ of DM and higher were analyzed for OMD using the enzymatic digestibility of OM method (EDOM; Weisbjerg and Hvelplund, 1993), a multienzymatic method described in detail by Álvarez et al. (2020). Digestible OM (DOM $\left.\mathbf{D O D M}_{\text {ED }}\right)$ was estimated as EDOM (\%) $\times \mathrm{OM}(\mathrm{g} / \mathrm{kg}$ of $\mathrm{DM})$. Ash was determined by sample incineration at $550^{\circ} \mathrm{C}$, nitrogen $(\mathrm{N})$ was determined by the Dumas method (Dumas, 1831) using a Leco instrument (Leco Corp.), and $\mathrm{CP}$ was estimated as $\mathrm{N} \times 6.25$. Crude fat (CFat) as petrol ether was extracted after $\mathrm{HCl}$ hydrolysis according to EU 152/2009 (European Commission, 2009), and NDF (ash corrected) was determined using the amylase-treated NDF method (ISO 16472:2006; ISO, 2006). Starch (ST) was analyzed as described by Kristensen et al. (2007). After hydrolyzation by $\alpha$-amylase and amyloglucosidase, glucose is converted to hydrogen peroxide (by glucose oxidase) and measured electrochemically using a silver-platinum probe (YSI Inc.). Organic raw materials with an inclusion lower than $2 \%$ of DM in sampled compound feeds, minerals, and vitamins were not analyzed, so values from the NorFor Feed Table (NorFor, 2020) were used.

The NEL20 value of ingredients was estimated using degradation rates and indigestible fractions from the NorFor Feed Table (NorFor, 2020) and the measured chemical composition (Åkerlind and Volden, 2011). For compound feeds, NEL20 values were calculated according to NorFor by adding the NEL20 values of each ingredient according to their proportion in the mixture, referred to here as the weighted sum. These methods were used to calculate NEL20 of ingredients and compound feed used as the reference value for model development (referred to here as the NEL20 reference).

\section{Statistical Analysis}

All statistical analysis was performed using $\mathrm{R}$ software (version 3.6.0; R Core Team).

Model Development. Three data sets were used to develop models: a data set of 75 compound feed samples (referred to here as the compound data set), a data set of 108 ingredients (referred to here as the ingredient data set), and a data set of both 75 compound feeds and 108 ingredients, in total 183 samples (referred to here as the all data set). The dependent variable was NEL20 (MJ $/ \mathrm{kg}$ of DM). Independent variables for potential inclusion in the models were $\mathrm{DOM}_{\mathrm{EDOM}}, \mathrm{CP}$, CFat, NDF, ST, and ash (\% of DM). The CP content of compound feeds was corrected for urea by subtracting the urea $\mathrm{CP}$ proportion from the compound feed $\mathrm{CP}$ content $\left(\mathbf{C P}_{\text {corr }}\right)$. The order of inclusion for variables in models was determined through stepwise forward selection by small sample size corrected Akaike information criterion (AICc; Hurvich and Tsai, 1989) using the "stepAIC" function and the "AICc" criteria from the MASS package (Venables and Ripley, 2002). Models were developed using a sequential approach, including one variable at a time. Models were created with and without feed company or year as random effects. Models with random effects were developed using the "lmer" function from the "Ime4" package (Bates et al., 
2015). Models without random effects were developed using the "Im" function from the "stats" package in R (R Core Team).

The variance inflation factor (VIF) assessed the multicollinearity of independent variables in models (Zuur et al., 2010) with 3.3 as the limit criterion (Kock and Lynn, 2012). If a VIF value higher than 3.3 was detected, the variable with the highest VIF was discarded until the VIF for all variables met the criterion. Model fit was evaluated by AICc and root mean squared error (RMSE). No mean or linear biases were evaluated, as no independent data were used to evaluate model fit.

Model Validation. As models were created with different data sets, they were compared by evaluating prediction performance on compound feed samples only. For models developed with the all data set and compound data set (as compound feed samples were part of the development data set), validation was performed by cross-validation (the leave-one-out technique) using predicted residual error sum of squares (PRESS) according to Allen (1974). For models developed with the ingredient data set, where compound feeds were not part of the data set, validation was performed by using compound feed samples as an independent data set. Root mean squared error of prediction (RMSEP) was calculated for all models to evaluate prediction performance. For cross-validation, RM-

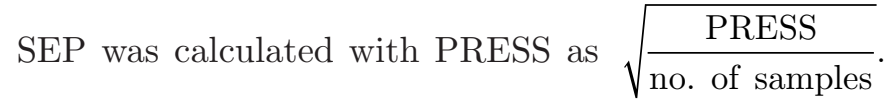
For models validated with compound feeds as an independent data set, RMSEP was calculated as $\sqrt{\sum \frac{(\text { predicted }- \text { reference })^{2}}{\text { no. of samples }}}$.

Additive Property. For $\mathrm{DOM}_{\mathrm{EDOM}}$, ash, $\mathrm{CP}_{\text {corr }}$, CFat, NDF, and ST, additivity was evaluated to test its effect on NEL20 prediction. Additivity was calculated according to Álvarez et al. (2020) by regressing the weighted sum of ingredients for the corresponding value (predicted) against the value directly measured in the compound feed (observed). Differences between predicted and observed values are referred to as additivity residuals. For regressions, the "lm" function from the "stats" package in R (R Core Team) was used. The additivity property was compared with EU-permitted tolerances for compositional labeling of compound feeds (European Commission, 2010). The EU tolerance levels define for all chemical components the acceptable differences between declared content and actual content in concentrates (for tolerances specifications, see Figure 1). Residual analysis was performed by regressing model-predicted values against residual values. For this analysis, model-predicted values were centered around the mean, making slope and intercept independent and orthogonal for mean and linear bias evaluation, respectively (St-Pierre, 2003).

To evaluate the effect of additivity residuals on NEL20 prediction by the model, for each compound sample additivity residuals of all chemical components were evaluated together. This was done by including the additivity residual of each chemical component as input in the selected model. Using this approach, all components were evaluated at the same time and weighted by their importance by the model's coefficient, also referred to as the weighted sum of additivity residuals. The weighted sums of additivity residuals were regressed against their NEL20 residual (NEL20 predicted - NEL20 reference), and Pearson correlation coefficient (r) was evaluated.

Model Use in Practice. To exemplify how the selected model could be used in practice, 30 independent compound feed samples (referred to here as the example data set) were collected from 4 companies with their corresponding NEL20 values as declared by each company (referred to here as NEL20 declared). Ingredient composition was supplied by each company, but no ingredient samples were collected; therefore, NEL20 reference values were not calculated. The NEL20 declared values were calculated in the NorFor software and reported by each company by including ingredients of the compound feed and their chemical composition and proportion. The values used for the NorFor calculations by the companies were a combination of measured and table values, with the proportion being company dependent and unknown for this study. The compound feed samples were analyzed for DM, ash, $\mathrm{DOM}_{\mathrm{EDOM}}$, CFat, NDF, CP, and ST as well as $\mathrm{CP}_{\text {corr }}$ calculated by the same methods used to analyze samples for model development. The NEL20 values predicted by the best model were regressed against the values declared by the company. Tolerance limits of EU ( $\pm 5 \%$; European Commission, 2010) were used as criteria to determine significant differences in this regression.

\section{RESULTS}

\section{Characteristics of Feed Samples}

Chemical composition, digestibility, and NEL20 reference of compound feeds and ingredient samples are summarized in Table 1 . Of the 75 compound feed samples, 40 contained more than 25\% DM ST and could be referred to as energy supplements, whereas 21 were protein supplements with more than $25 \%$ DM $\mathrm{CP}_{\text {corr }}$. The NEL20 range for compound feed presented a minimum of $6.06 \mathrm{MJ} / \mathrm{kg}$ of $\mathrm{DM}$ and a maximum of 
a

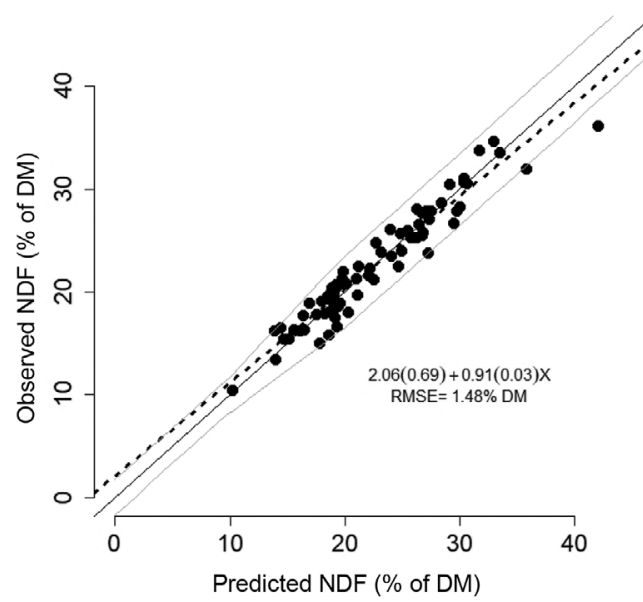

C

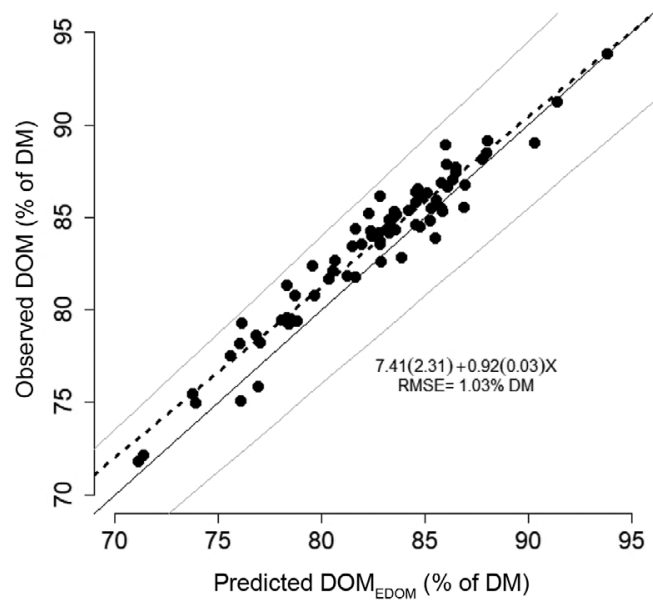

e

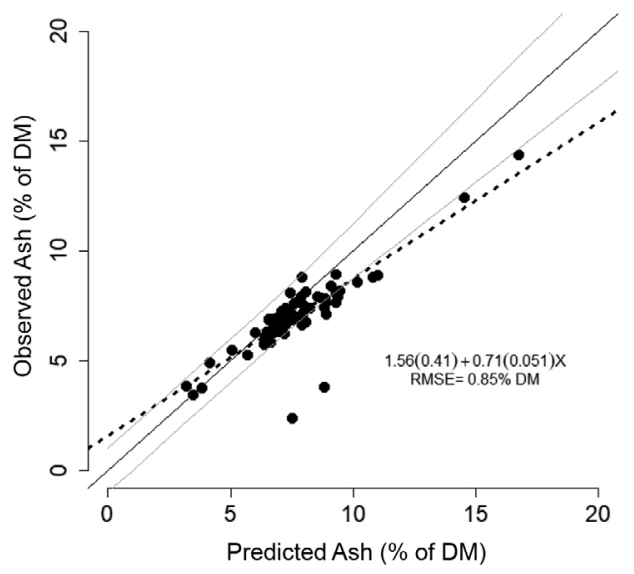

b

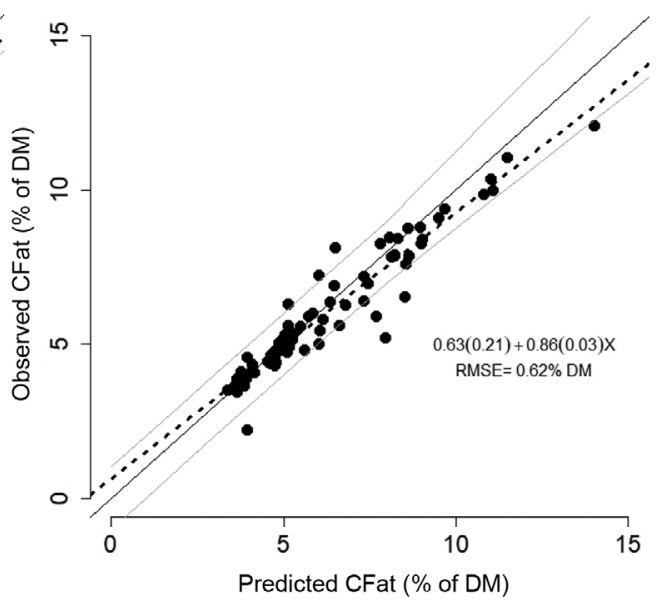

d

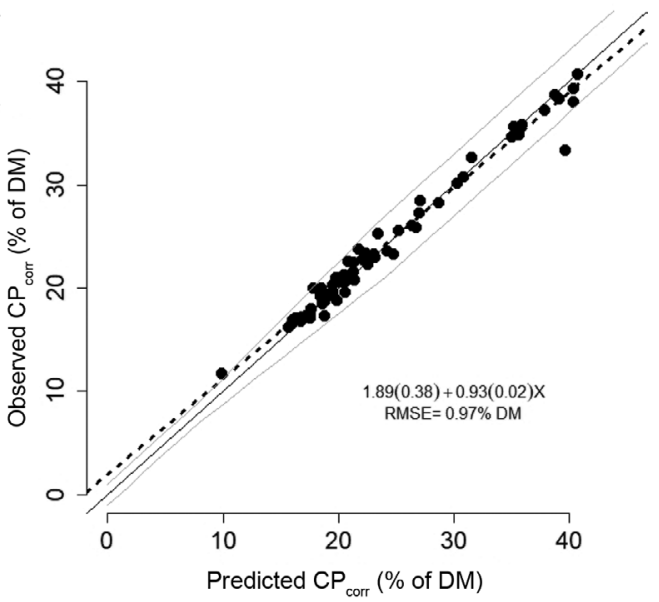

f

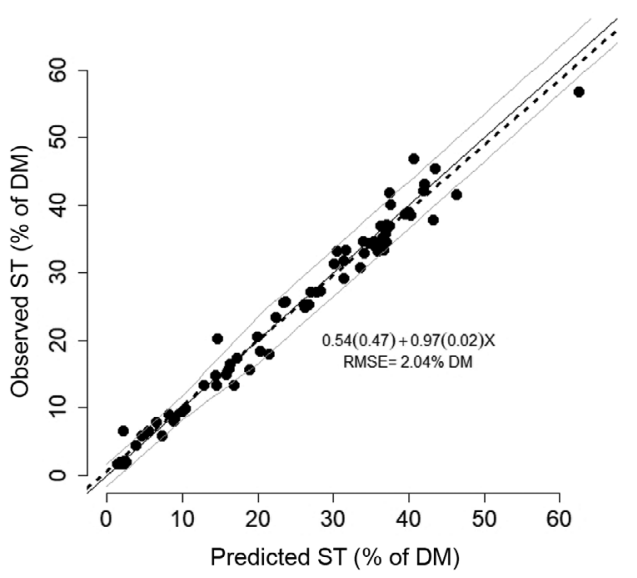

Figure 1. Regression between predicted nutrients (calculated by the weighted sum of ingredients; x-axis) and measured nutrients in compound feed (y-axis) for (a) NDF, (b) crude fat (CFat), (c) digestible OM by enzymatic digestibility of OM method (DOM EDOM$_{\text {) }}$, (d) CP corrected by urea $\left(\mathrm{CP}_{\text {corr }}\right),(\mathrm{e})$ ash, and (f) starch $(\mathrm{ST})$. Solid line: $\mathrm{x}=\mathrm{y}$; gray lines: European Union (EU) tolerance (allowed difference between declared value and actual content for the corresponding nutrient). Tolerance levels used for NDF (correspond to EU tolerance for crude fiber) and ST: $\pm 3.5 \%$ of total mass or volume for contents of $20 \%$ or more; $17.5 \%$ of the content for contents of less than $20 \%$ but not less than $10 \%$; $\pm 1.7 \%$ of the total mass or volume for contents of less than $10 \%$. Tolerance levels used for CFat, $\mathrm{CP}_{\text {corr }}$, and ash: $\pm 3 \%$ of the total mass or volume for contents of $24 \%$ or more; $12.5 \%$ of the content for contents of less than $24 \%$ but not less than $8 \%$; $\pm 1 \%$ of the total mass or volume for contents of less than $8 \%$. Tolerance levels used for $\mathrm{DOM}_{\mathrm{EDOM}}$ (correspond to EU tolerance for energy): $\pm 5 \%$ of the content. Dashed lines: regression line. Regression equation: coefficient (SE). RMSE = root mean squared error. 
$8.43 \mathrm{MJ} / \mathrm{kg}$ of $\mathrm{DM}$, with $7.14 \mathrm{MJ} / \mathrm{kg}$ of $\mathrm{DM}$ as the mean value.

Ingredient samples presented a wider range than compound feeds for all variables (Table 1). Ingredient samples were used to produce compound feed samples, and a detailed description of their composition, frequency of inclusion in the compound feed samples, and quantity of samples included in the data set is shown in Table 2. Rapeseed cake followed by soybean meal and rapeseed meal were the most frequently used proteinrich ingredients in compound feeds. Barley was the most frequently used starch source, followed by wheat, oats, and rye. Sugar beet pulp and wheat bran were the most included fiber-rich ingredients. Other frequently used ingredients were distillers grains, maize, and maize gluten meal.

\section{Model Development and Validation}

Stepwise AICc selection for prediction of NEL20 showed the same order of variable inclusion for the all data set and ingredient data set, with CFat as the first variable included, followed by $\mathrm{NDF}, \mathrm{CP}_{\text {corr }}, \mathrm{DOM}_{\mathrm{EDOM}}$, ash, and ST. For the compound data set, NDF was the first variable, followed by $\mathrm{CFat}, \mathrm{DOM}_{\mathrm{EDOM}}, \mathrm{CP}_{\text {corr }}$, $\mathrm{ST}$, and ash. Models with ST presented a VIF higher than 3.3 ; thus, ST was removed from those models. After ST was removed, VIF met the criteria. Models including company and year as a random effect presented higher AICc in all model comparisons, so models only including fixed effects were chosen. Table 3 shows AICc and RMSE for all models used for model fit evaluation and RMSEP used to evaluate prediction performance. Model I presented the best fit $(\mathrm{AICc}=-71.8, \mathrm{RMSE}$
$=0.149 \mathrm{MJ} / \mathrm{kg}$ of $\mathrm{DM})$ and predictive performance $($ RMSEP $=0.149 \mathrm{MJ} / \mathrm{kg}$ of $\mathrm{DM})$, followed by model J. Model E, developed with the largest data set (183 samples) and NEL20 range (3.05-18.8 MJ/kg of DM) presented a fit and predictive performance comparable with that of models J and I. Therefore, models E and I were chosen as the best models for NEL20 prediction in compound feeds, and further analysis was conducted based on these models.

Twelve out of 75 compound feed samples contained urea. Urea inclusion in these 12 samples was $1.21 \%$ of DM on average, with a minimum inclusion of $0.341 \%$ of DM and a maximum inclusion of $3.30 \%$ of DM. The effect of not correcting CP for inclusion of urea in the compound feeds was tested in models E2 and I2. Models E and I presented better fit than their corresponding models not corrected for urea (Table 3).

\section{Additivity}

The additive properties of NDF, CFat, $\mathrm{DOM}_{\mathrm{EDOM}}$, $\mathrm{CP}_{\text {corr }}$, ash, and $\mathrm{ST}$ are shown in Figure 1a to $\mathrm{f}$ for the 75 compound feed samples. Of the 75 samples, 49 were also evaluated by Álvarez et al. (2020). To assess additivity, EU tolerance limits for each chemical component were used as criteria (for specific tolerance limits, see Figure 1). For NDF, the EU does not specify tolerances; thus, limits defined for crude fiber were used. Of the 75 samples, only 2 were outside these limits (Figure 1a). From residual analysis, intercept $(P$ $=0.76)$ and slope $(P=0.49)$ presented no mean or linear bias, respectively. For CFat, 8 out of 75 samples were outside the EU tolerance limits (Figure 1b). From residual analysis, additivity of CFat presented a signifi-

Table 1. Summary statistics of the chemical composition of compound feeds and their ingredients used for model development of NEL20

\begin{tabular}{|c|c|c|c|c|c|c|c|c|}
\hline Item $^{1}$ & \multicolumn{4}{|c|}{ Compound feeds } & \multicolumn{4}{|c|}{ Ingredients } \\
\hline Number of samples & 75 & 75 & 75 & 75 & 108 & 108 & 108 & 108 \\
\hline $\operatorname{Ash}(\%$ of DM) & 7.02 & 2.39 & 14.37 & 1.63 & 4.73 & 0.20 & 22.60 & 3.04 \\
\hline $\mathrm{CP}(\%$ of $\mathrm{DM})$ & 23.9 & 11.7 & 42.7 & 7.21 & 23.7 & 0.131 & 66.7 & 16.4 \\
\hline $\mathrm{CP}_{\text {corr }}(\%$ of $\mathrm{DM})$ & 23.4 & 11.7 & 40.7 & 6.79 & & & & \\
\hline ST $(\%$ of $\mathrm{DM})$ & 23.6 & 1.60 & 56.8 & 14.1 & 24.0 & 0.00 & 72.6 & 26.6 \\
\hline NEL20 reference (MJ/kg of DM) & 7.14 & 6.06 & 8.43 & 0.49 & 7.36 & 3.05 & 18.8 & 2.24 \\
\hline
\end{tabular}

${ }^{1} \mathrm{DOM}_{\mathrm{EDOM}}$ : digestible $\mathrm{OM}$ by enzymatic digestibility of $\mathrm{OM}$ method; $\mathrm{CP}_{\text {corr }}$ : $\mathrm{CP}$ corrected by urea content in compound feeds; $\mathrm{CFat}$ : crude fat; ST: starch; NEL20 reference: net energy of lactation at $20 \mathrm{~kg}$ of DMI/d. NEL20 reference of ingredients: calculated using table values and measured chemical composition. NEL20 reference of compound feeds: calculated by the weighted sum of its ingredients.

${ }^{2}$ Average content.

${ }^{3}$ Minimum content.

${ }^{4}$ Maximum content. 


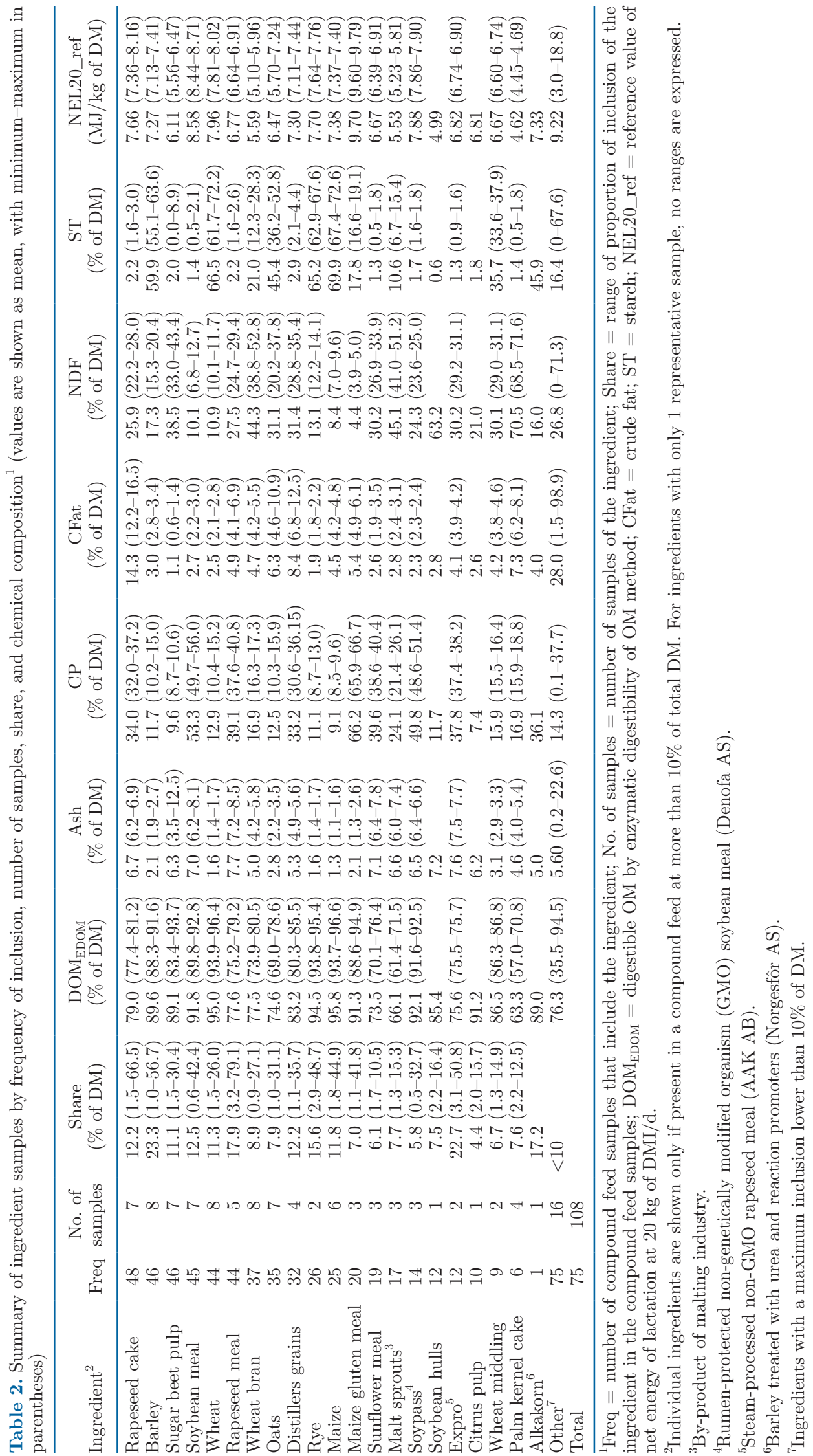


Álvarez et al.: DAIRY INDUSTRY TODAY

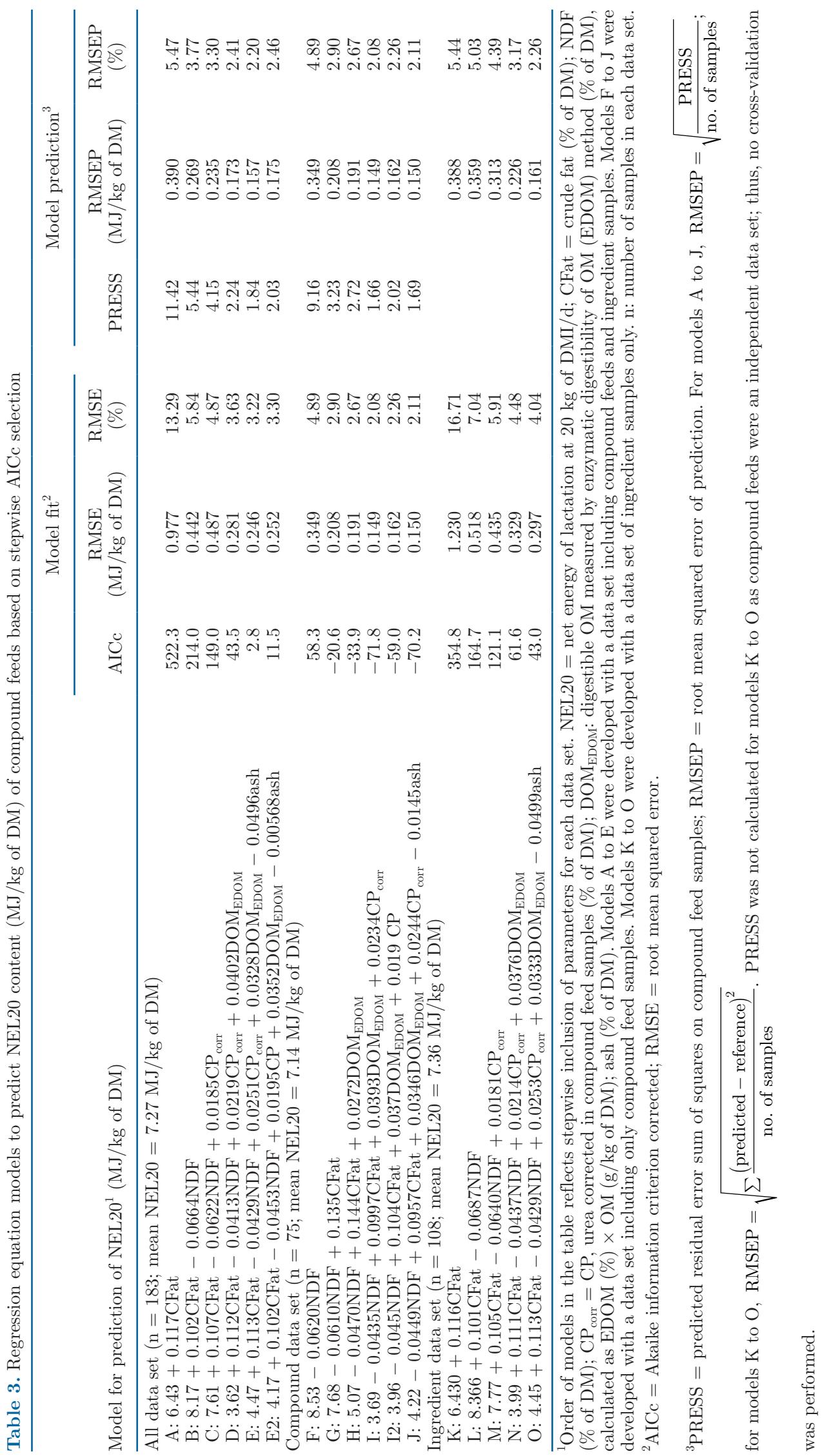



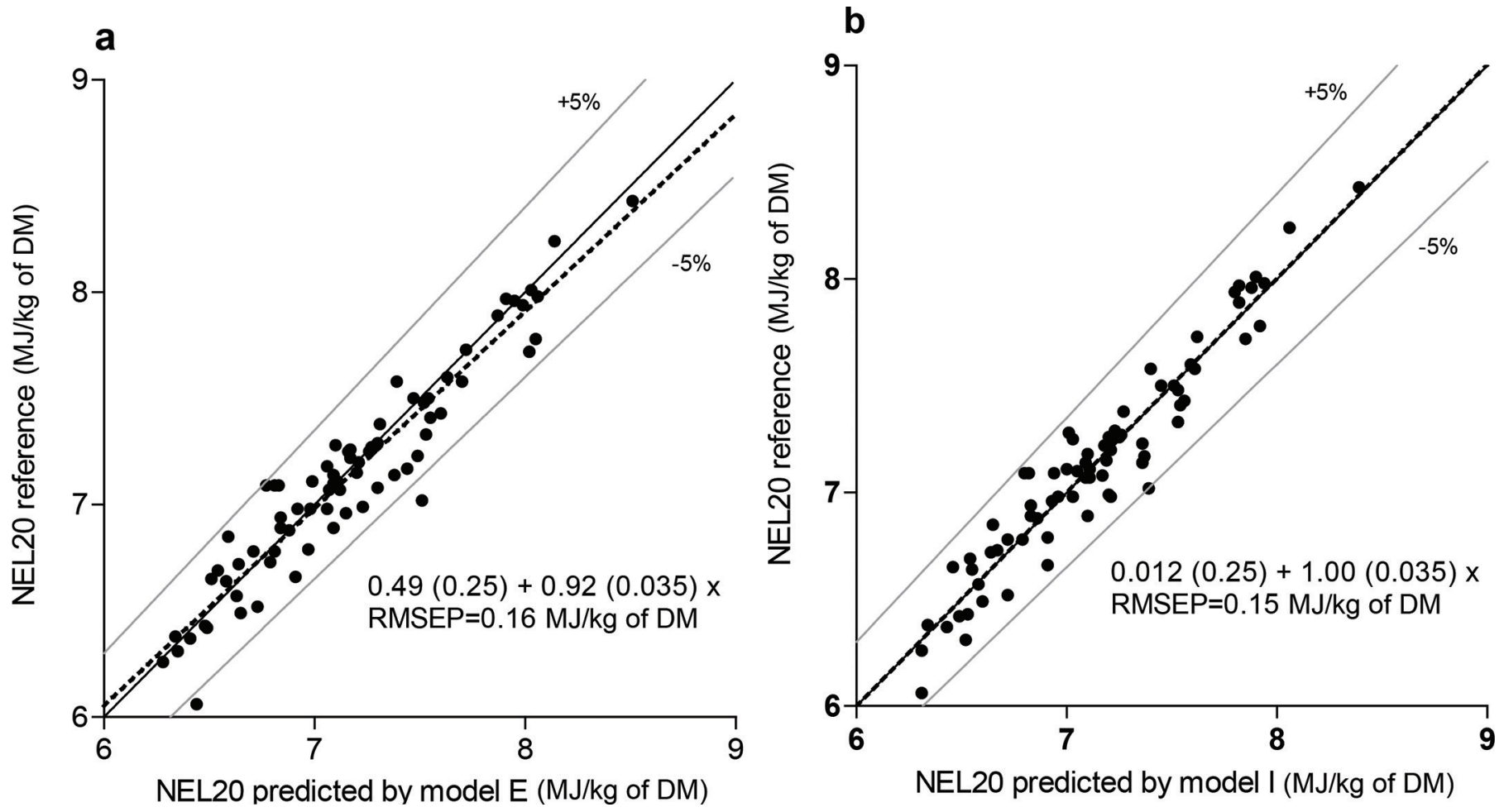

Figure 2. (a) Regression between net energy for lactation at $20 \mathrm{~kg}$ of DMI/d (NEL20) values of 75 compound feed samples predicted by model E (x-axis) and their respective NEL20 reference values (y-axis). (b) Regression between NEL20 values of 75 compound feed samples predicted by model I (x-axis) and their respective NEL20 reference values (y-axis). Solid lines: $\mathrm{x}=\mathrm{y}$; dashed lines: regression line; gray lines: European Union tolerance (difference between energy declared value and actual energy content; $\pm 5 \%$ of the content). Regression equation: coefficient $(\mathrm{SE})$. RMSEP $=$ root mean squared error of prediction.

cant negative mean bias $(-0.23 \% \mathrm{DM}, P<0.05)$ but no linear bias $(P=0.17)$. The $\mathrm{EU}$ does not provide a tolerance limit for $\mathrm{DOM}_{\mathrm{EDOM}}$, and tolerance stated for energy was used. No samples were outside these limits (Figure 1c), but residual analysis showed a significant positive mean bias $(1.03 \% \mathrm{DM}, P<0.05)$ but no linear bias $(P=0.61)$. For $\mathrm{CP}_{\text {corr }}, 2$ samples were outside $\mathrm{EU}$ tolerance limits. Residual analysis showed a significant linear bias $(P<0.05)$, meaning overestimation of low observed $\mathrm{CP}_{\text {corr }}$ values and underestimation of high observed $\mathrm{CP}_{\text {corr }}$ values (Figure 1d). No significant mean bias was detected for $\mathrm{CP}_{\text {corr }}(P=0.15)$. Ash showed the highest number of samples (17) outside EU tolerance limits. Residual analysis showed significant mean bias $(-0.63 \%$ DM,$P<0.05)$ and linear bias $(P<0.05)$ overestimating low observed values and underestimating high observed values (Figure 1e). The additivity relationship for ST showed that 8 samples were outside EU tolerance limits (Figure 1f). Starch did not show mean bias $(P=0.28)$ or linear bias $(P=0.46)$.

Regression between NEL20 values predicted by models E and I against NEL20 reference for compound feeds is shown in Figure 2a and b, respectively. Differ- ences between predicted and NEL20 reference values were observed. From these differences, 2 samples were outside the EU tolerance lower limit $(-5 \%)$ for model E, whereas no samples were outside the limits for model I. Evaluation of the effect of additivity differences on the NEL20 prediction of models E and I (Figure 3a and $\mathrm{b}$ for models $\mathrm{E}$ and I, respectively) show a strong association between weighted additivity residuals and NEL20 residuals $(\mathrm{r}=-0.73, P<0.001$ for model $\mathrm{E}$ and $\mathrm{r}=-0.69, P<0.001$ for model $\mathrm{I})$.

Prediction of ingredient NEL20 by models E and I is shown in Figure 4. For both models, the RMSEP of ingredients was higher than for compound feeds. Figure 4 shows that ingredients such as wheat bran, maize, rapeseed meal, and rapeseed cake were overpredicted by the models (positive residuals), whereas ingredients such as sugar beet pulp, barley, rye, wheat, soybean meal, and maize gluten meal were underpredicted by the models (negative residuals). Moreover, these residuals are higher for model I than for model E. Figure 4 also shows that ingredients in the extremes of the graph (e.g., oat hulls, whole rapeseeds, and fat supplements) showed the highest residuals for model I. 

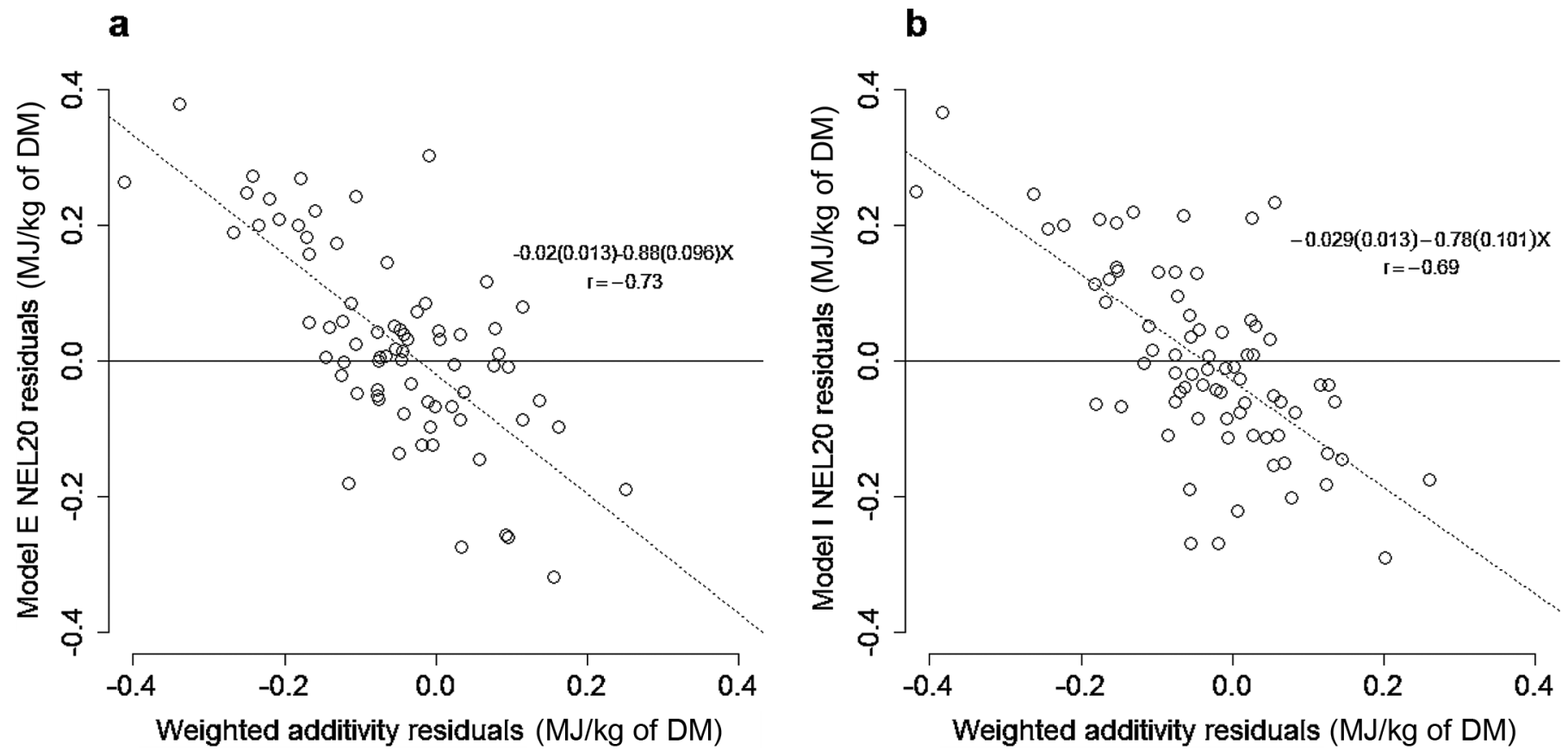

Figure 3. (a) Regression between weighted additivity differences (x-axis) and net energy for lactation at 20 kg of DMI/d (NEL20) residuals from compound feeds using model E (y-axis). (b) Regression between weighted additivity residuals (x-axis) and NEL20 residuals from compound feeds using model I (y-axis). Weighted additivity residuals: additivity differences of the chemical components weighted by including them in model E (a) and model I (b); dotted lines: regression line. Regression equation: coefficient (SE).

\section{Model Use in Practice}

Only compound feed samples were collected; therefore, no NEL20 reference values were obtained and only NEL20 declared values by the manufacturers were evaluated, simulating the practical use of models $\mathrm{E}$ and I. Chemical composition and NEL20 declared values are shown in Table 4. Chemical composition showed similarities to compound feeds used for model development (Table 1), although maximum values of ash, $\mathrm{CP}_{\text {corr }}$, and NEL20 were higher in the example data set, but $\mathrm{DOM}_{\mathrm{EDOM}}$ and ST were lower. However, as model E was developed using the all data set (including both compound and ingredients) for model development, the range of all variables was larger than in the example data set. Comparison between the NEL20 values predicted by models E and I and the NEL20 declared by companies is shown in Figure 5a and b, respectively. Mean NEL20 declared value was $7.64 \mathrm{MJ} / \mathrm{kg}$ of DM. For model E, mean NEL20 predicted value was 7.33 $\mathrm{MJ} / \mathrm{kg}$ of DM, and 11 compound feeds samples out of 30 lay outside the upper 5\% EU tolerance level. For model I, mean NEL20 predicted was $7.30 \mathrm{MJ} / \mathrm{kg}$ of $\mathrm{DM}$, and 12 compound feed samples lay outside the upper 5\% EU tolerance level. For both models, for all but 1 sample, declared NEL20 values were higher than the values predicted by models $\mathrm{E}$ and $\mathrm{I}$.

\section{DISCUSSION}

In the NorFor system, NEL20 is the most used standard net energy value. For compound feeds, NEL20 calculation depends on ingredient composition. However, manufacturers are not obliged to declare energy content or ingredient share. Therefore, a method to measure NEL20 directly from the compound feed is essential for accurate diet formulation using NorFor, as compound feeds can represent more than half of the feed ration. With this study, we intended to formulate static empirical equations to predict the NEL20 of compound feeds independent of their ingredients, based on chemical composition and in vitro enzymatic OMD (EDOM), determined according to Weisbjerg and Hvelplund (1993) and evaluated by Álvarez et al. (2020). If the method has sufficient accuracy and all the actors using the NorFor system (farmers, advisors, feed companies, and NorFor itself) agree, a common method will enable final company verification of products, allow farmers to confirm declared net energy values, and improve trustworthiness of the industry.

Other feed evaluation systems feature empirical models for the energy prediction of compound feeds. The INRA system uses an equation proposed by Sauvant et al. (2002) based on chemical composition and OMD. In this system, OMD is predicted by 


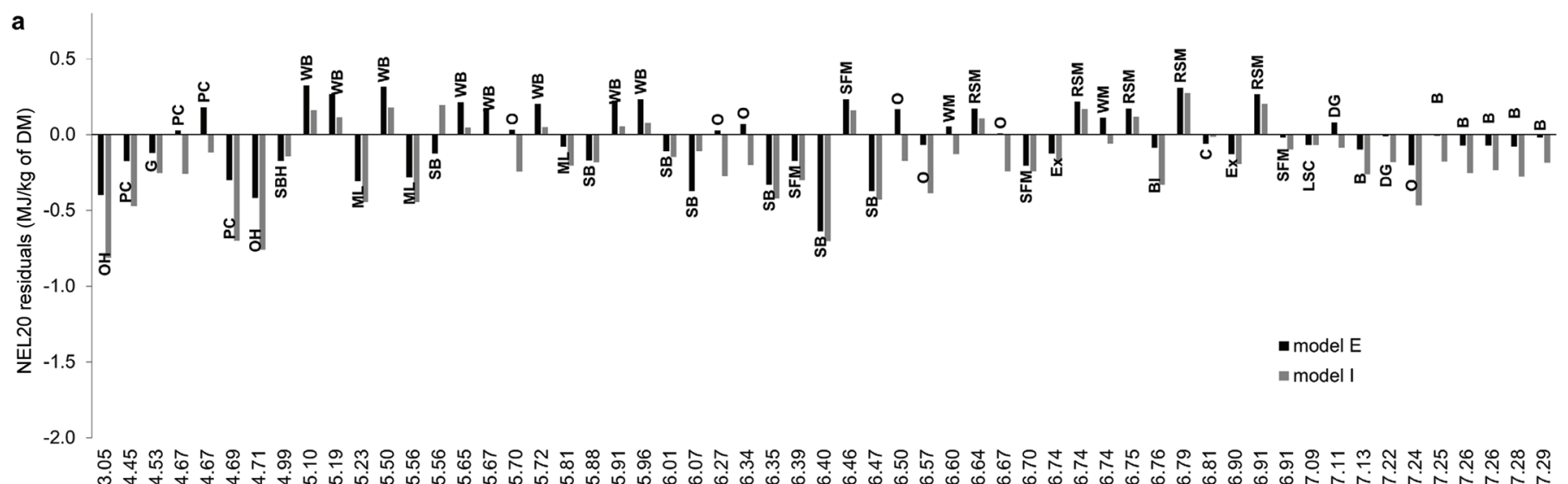

NEL20 reference of ingredients (MJ/kg of DM)

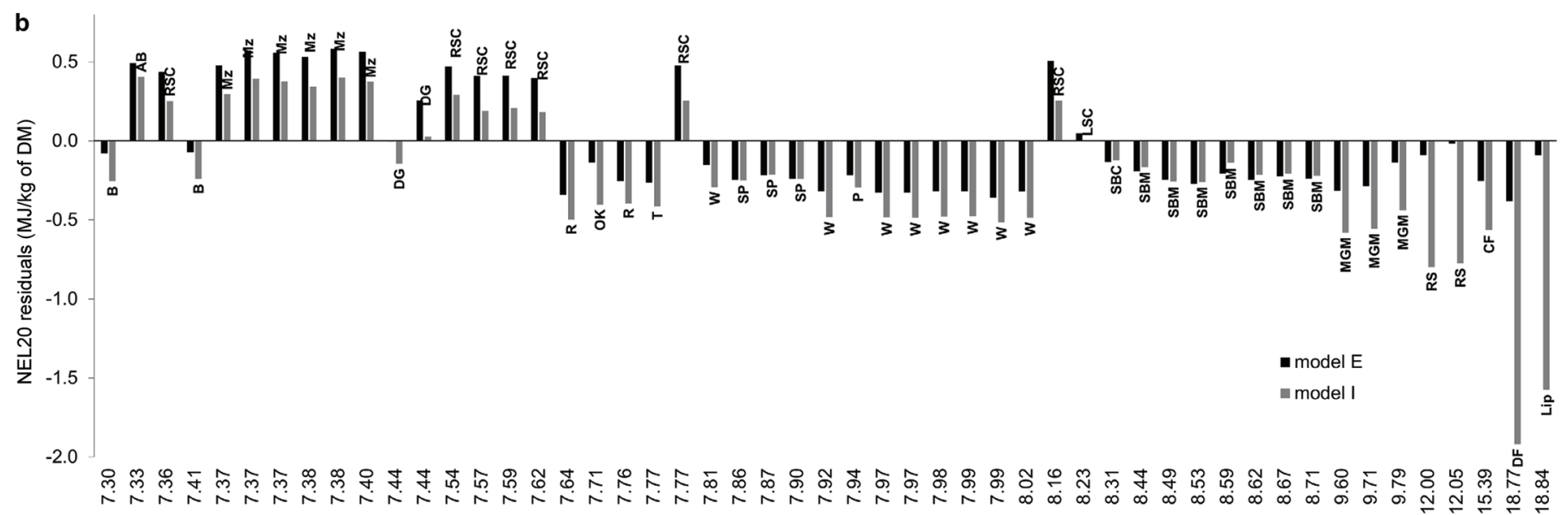

$\mathrm{NEL20}$ reference of ingredients (MJ/kg of DM)

Figure 4. Net energy for lactation at $20 \mathrm{~kg}$ of DMI/d (NEL20) residuals of ingredients predicted by models E and I (predicted - observed; MJ/kg of DM; y-axis) against NEL20 reference values (MJ/kg of DM; x-axis): (a) NEL20 reference from 3.05 to 7.29 MJ/kg of DM; (b) NEL20 reference from 7.30 to $18.84 \mathrm{MJ} / \mathrm{kg}$ of $\mathrm{DM}$. $\mathrm{AB}=$ alkaline barley; $\mathrm{B}=$ barley; $\mathrm{Bl}=$ mix of grains; $\mathrm{C}=$ citrus pulp; $\mathrm{CF}=$ calcium fat; $\mathrm{DF}=\mathrm{dry}$ fat; DG = distillers grains; Ex = ExPro heat-treated rapeseed meal (AAK AB); G = dry Lucerne pellets; Lip = Lipitec (saturated fat; NLM Vantinge AS); LSC = line seed cake; $\mathrm{M}=$ maize; $\mathrm{MGM}=$ maize gluten meal; $\mathrm{ML}=$ malt sprouts; $\mathrm{O}=\mathrm{oat}$; $\mathrm{OH}=\mathrm{oat}$ hulls; $\mathrm{OK}=\mathrm{oat}$ kernel; $\mathrm{P}=$ peas; $\mathrm{PC}=$ palm kernel cake; $\mathrm{R}=$ rye; $\mathrm{RS}=$ rapeseed (crushed); $\mathrm{RSC}=$ rapeseed cake; $\mathrm{RSM}=$ rapeseed meal; $\mathrm{SB}=\mathrm{sugar}$ beet pulp; $\mathrm{SBC}$ = soybean cake; $\mathrm{SBM}=$ soybean meal; $\mathrm{SFM}=$ sunflower meal; $\mathrm{SP}=$ Soypass (Denofa AS); $\mathrm{T}=$ triticale; $\mathrm{W}=$ wheat; WB = wheat bran; WM = wheat middling. Root mean squared error of prediction (RMSEP) of ingredients for model E $=0.29 \mathrm{MJ} / \mathrm{kg}$ of DM; RMSEP of ingredients for model I $=0.41 \mathrm{MJ} / \mathrm{kg}$ of DM (see models in Table 3 ).

$\mathrm{ADF}$ and ADL or measured by enzymatic digestibility (Baumont et al., 2018). The Feed Into Milk system (Thomas, 2004) recommends an equation based on compound feed enzymatic digestibility (Thomas et al., 1988). Germany uses prediction equations based on an enzymatic method for OMD determination (GfE, 2009). Denmark established an official prediction equation also based on OMD, measured by the EDOM method, for the Danish feed-unit system (Weisbjerg and Hvelplund, 1993) and chemical composition. Thus, chemical composition and OMD were included as potential variables in this study. Selection of $\mathrm{DOM}_{\mathrm{EDOM}}$ for OMD representation was based on the premise that models should be not only accurate and precise but also easy to adopt. The EDOM method has been proven accurate (Weisbjerg and Hvelplund, 1996) and precise (Álvarez et al., 2020). Moreover, it is already a familiar method used in commercial laboratories in Scandinavia, as it is the official method for energy declaration in compound feeds in the static Danish feed-unit system (Danish Veterinary and Food Administration, 2020) and is used for OMD determination in some forage types. In this study, inclusion of $\mathrm{DOM}_{\mathrm{EDOM}}$ as a variable agrees with the results of Cottyn et al. (1984) and De Boever et al. (1994), who found that models that only included chemical composition were less accurate than models that also included OMD as a variable (Table 3). 


\section{Prediction of NEL20}

Two years of sample collection from several Scandinavian feed companies revealed a large variation in samples' net energy values $(6.06-8.43 \mathrm{MJ} / \mathrm{kg}$ of $\mathrm{DM}$ in compound feeds and $3.05-18.8 \mathrm{MJ} / \mathrm{kg}$ of $\mathrm{DM}$ in ingredient samples), representative of the industry. Industry representation was also reflected in the collected samples, as most ingredients used in compound feed production, such as cereals, rapeseed by-products, and soybean meal were represented by the highest sample number in our data set (Table 2). This variation allowed the model development to be as representative of the Scandinavian feed industry as possible, supporting the adoption of the selected model in practice.

The use of 3 data sets in this study allowed models to be created and evaluated using different net energy ranges and feed types (compounds, or ingredients, or both), providing a more solid base for model evaluation. However, inclusion of ingredients as part of the data set is debatable, as the objective is to use the model on compound feeds. Moreover, including the ingredients could result in dependency in the data set, as compound feeds included in the data set are produced by the ingredients. Nevertheless, we decided to include the evaluation of model $\mathrm{E}$ to compare its performance with the best fitting model, model I.

The equation error of model I $(\mathrm{RSD}=1.99 \%$ of mean $)$ was lower than the average error of $3.97 \%$ of mean (average of 2.57 and $5.36 \%$ for normal and fiber-rich concentrates, respectively) reported by De Boever et al. (1994) and $4.32 \%$ of mean reported by Giger-Reverdin et al. (1994). The German system (GfE, 2009), static and empirical, reported an equation error of $2.04 \%$ of mean (RMSE), similar to model I. The Danish feed-

Table 4. Chemical composition (\% of DM) and NEL20 values (MJ/ $\mathrm{kg}$ of $\mathrm{DM}$ ) of compound feeds collected from 4 feed companies in Scandinavia and used as an example of models E and I

\begin{tabular}{|c|c|c|c|c|}
\hline Item $^{1}$ & Mean & Minimum & Maximum & SD \\
\hline No. of samples & 30 & 30 & 30 & 30 \\
\hline $\mathrm{DOM}_{\mathrm{EDOM}}$ & 82.5 & 76.1 & 87.9 & 2.62 \\
\hline Ash & 7.91 & 6.20 & 16.6 & 1.91 \\
\hline $\mathrm{CP}$ & 27.6 & 18.6 & 44.2 & 6.93 \\
\hline $\mathrm{CP}_{\text {corr }}$ & 27.4 & 18.6 & 44.2 & 6.62 \\
\hline CFat & 7.53 & 5.20 & 12.0 & 1.62 \\
\hline NDF & 23.4 & 14.9 & 28.4 & 3.13 \\
\hline ST & 15.2 & 1.60 & 31.8 & 10.6 \\
\hline NEL20 declared & 7.64 & 6.97 & 9.00 & 0.443 \\
\hline
\end{tabular}

${ }^{1} \mathrm{DOM}_{\mathrm{EDOM}}=$ digestible $\mathrm{OM}$ by enzymatic digestibility of OM method; $\mathrm{CP}_{\text {corr }}=\mathrm{CP}$ corrected by urea content in compound feeds; CFat = crude fat; ST = starch; NEL20 declared = net energy of lactation at $20 \mathrm{~kg}$ of DMI/d, declared by the feed companies. Calculated by each company as weighted sum of NEL20 of ingredients using table and measured chemical composition. Proportion of table and measured values depended on each company and is unknown for this study. unit system (Weisbjerg and Hvelplund, 1993), which is also static and empirical, showed a higher RSD than model I for digestible energy (3.13\% of mean).

Better prediction of compound feeds of model I (RMSEP $=2.08 \%$ of mean) compared with model $\mathrm{E}$ (RMSEP $=2.20 \%$ of mean) could be explained by the inclusion of the same compound feeds for model development and for this evaluation. On the contrary, model E included a larger range, as not only these compound feed samples but also the ingredient samples were included.

Higher error of prediction for ingredient NEL20 of model I was expected, as ingredients were not included in the data set for development of this model but were included in the development of model E. Prediction error for model E was lower than the EU 5\% limit (3.98\% of mean) and therefore could potentially be used to estimate NEL20 of ingredients. However, to be included as a useful model for ingredient prediction, validation against an independent set of ingredients should be performed. As the prediction error of ingredients of model I was higher than the EU tolerance limit $(5.58 \%$ of mean), model I could potentially not be useful for prediction of NEL20 of ingredients, although an independent validation is also recommended. When ingredients were not included in the developing data set, as for model I, extreme contents of chemical components had an effect on the prediction of ingredients. For example, oat hulls with high content of NDF, rapeseed with high content of CFat, and pure fat supplements showed a significant underestimation of NEL20 values by model I but not by model E. This could be due to the NEL20 of these ingredients being outside the NEL20 range used for development of model I. High prediction error of ingredients supports the use of detailed characteristics in the dynamic model for prediction of ingredients, such as indigestible fractions and passage rates, if available. These characteristics are available for ingredients in most cases.

The additivity results from this study can be compared with the results of Álvarez et al. (2020), although they share 49 out of 75 compound feeds. Additivity errors (RMSE) in our study showed errors similar to those identified by Álvarez et al. (2020) for $\mathrm{DOM}_{\mathrm{EDOM}}(1.03 \%$ vs. $1.07 \%$ of DM), NDF (1.48\% vs. $1.46 \%$ of $\mathrm{DM})$, and ST $(2.04 \%$ vs. $1.90 \%$ of $\mathrm{DM})$, whereas $\mathrm{CP}_{\text {corr }}$ showed lower error in our study ( $0.97 \%$ vs. $1.56 \%$ of $\mathrm{DM})$ but higher error for CFat ( $0.62 \%$ vs. $0.39 \%$ of DM). Additivity values for ash were only evaluated in our study and showed high differences between weighted sum of ingredient calculation and ash analyzed directly in the compound feed. These differences could be allocated to the siliceous proportion of the ash, as dry incineration could produce a cover over the sample, preventing 
a

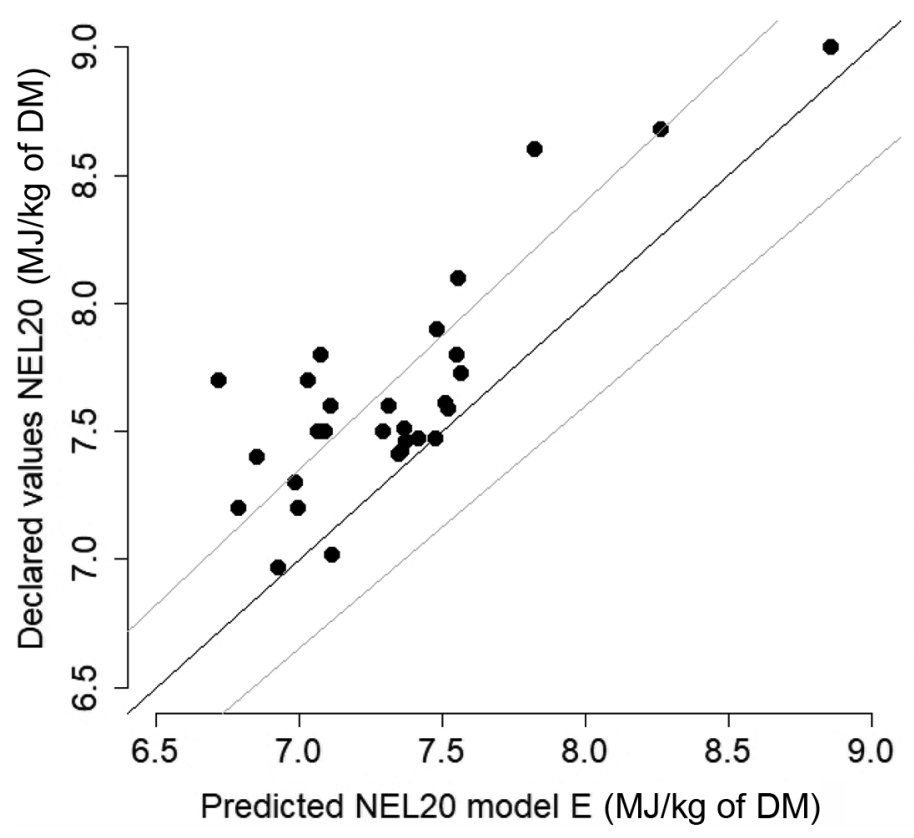

b

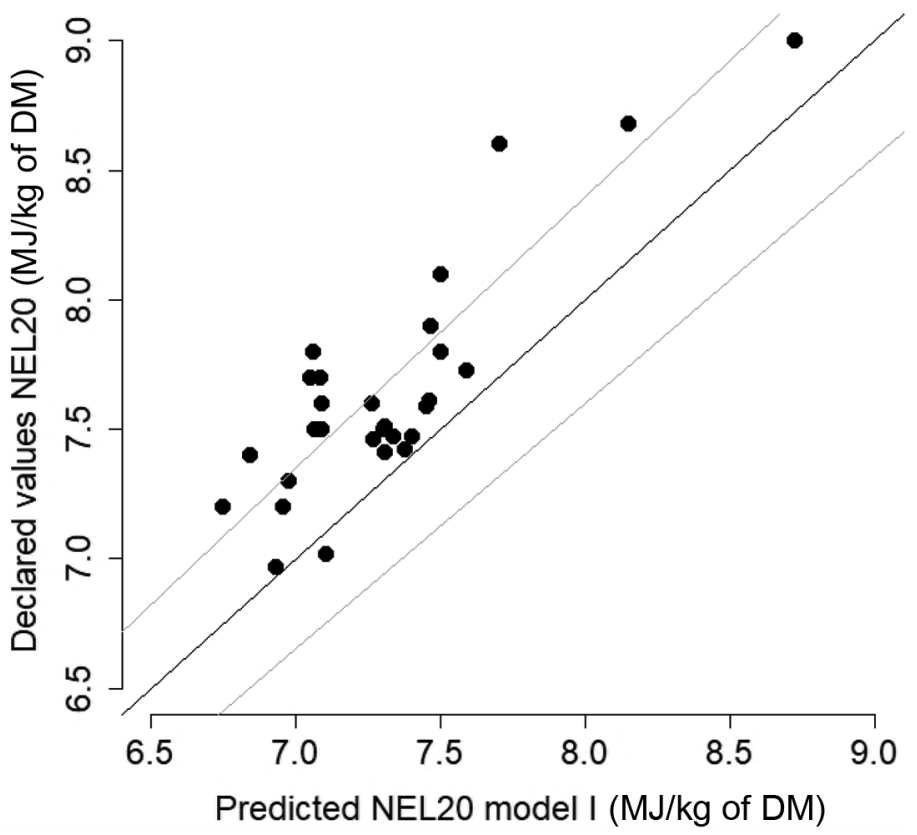

Figure 5. (a) Relationship between net energy for lactation at $20 \mathrm{~kg}$ of DMI/d (NEL20) values in 30 compound feed NEL20 values predicted by model E (x-axis) and declared by the feed companies (y-axis). (b) Relationship between NEL20 values in 30 compound feed NEL20 values predicted by model I (x-axis) and declared by the feed companies (y-axis). Solid lines: $\mathrm{x}=\mathrm{y}$; gray lines: European Union declaration limit of $\pm 5.0 \%$. NEL20 predicted by model $\mathrm{E}=7.33 \mathrm{MJ} / \mathrm{kg}$ of DM; NEL20 predicted by model I = 7.30 MJ $/ \mathrm{kg}$ of DM; NEL20 declared $=7.64 \mathrm{MJ} /$ $\mathrm{kg}$ of DM.

complete combustion (Nørgaard Pedersen, 1962; Liu, 2019). As ingredients samples get analyzed in their pure form or mixed in the compound feed, the siliceous proportions of the analyzed samples get modified, thus potentially affecting the combustion performance. Higher incineration temperatures $\left(600^{\circ} \mathrm{C}\right)$ and longer incineration time could be used in the reanalysis (Liu, 2019).

Although additivity correlation for all variables was high, some differences in additivity were found (Figure 1a to f). The effect of the lack of additivity of chemical analyses on residual values for NEL20 was expected and showed a correlation of -0.73 for model E (Figure 3a) and -0.69 for model I (Figure $3 b$ ). This indicates that, although not completely, a large proportion of the differences between NEL20 reference and predicted values could be attributed to differences between ingredients and compound feed analysis. The effect of lack of additivity can be explained by the fact that NEL20 reference values are calculated with ingredients, whereas the NEL20 values predicted by model I are based on nutrients analyzed in compound feeds. Thus, any difference in chemical components between the ingredient weighted sum and compound feeds (lack of additivity) will be reflected in NEL20 residuals. Identification of this error source in the model is meaningful because it can explain potential differences between declared and predicted NEL20 values. Moreover, these differences can be easily detected by performing an additivity comparison, as shown in Figure 1a to f. Lack of additivity could be caused by analytical errors, potential interactions among ingredients, sampling errors, or mixing errors when creating the compound feed. Another potential error is the methods used for analyzing chemical components. For nitrogen analysis, NorFor recommended the Dumas or Kjeldahl methods; thus, using different methods could potentially result in differences. However, these methods have shown high correlation (0.99) in grain and other feedstuffs (Hansen, 1989; Watson and Galliher, 2001), although it was not tested in our study. For the other chemical components, NorFor recommends only one method for each, and those methods were the ones used in this study. Moreover, intrinsic errors of the model will also contribute to the differences between NEL20 reference and predicted values.

\section{Model Use and Maintenance}

Dynamic ration evaluation systems such as NorFor can be supplemented by static empirical models. This type of static model could serve as a proxy when data 
for calculating the reference method is time consuming and expensive to measure. It could be used as a corroboration method by feed manufacturers to determine whether the final compound feed matches the planned energy content. It could also be used at the farm level to evaluate a concentrate mix produced on the farm. The model would reduce farmer expenses, as analysis could be done on the final product instead of on all ingredients. Moreover, the model could be used by the purchaser to ensure that the purchased compound feeds correspond to the declared energy values. The example given in Figure 5a and b shows, for both models, that the net energy content in 12 out of 30 samples lay outside the EU acceptance limit of $\pm 5 \%$. However, that this is an example for the model use in practice and we are not comparing NEL20 reference values, as no ingredients were analyzed. The finding suggests that not only differences in additivity or the intrinsic model error could be sources of error. Deviation between declared and real inclusion of ingredients, direct mixing errors, and variation in chemical composition and digestibility of ingredients could result in differences between NEL20 values predicted by these models and declared by the companies. In this respect, feed companies could use a systematic evaluation method such as this as a useful tool for quality control of compound feeds. Moreover, a systematic evaluation method could be a useful tool for authorities, as it would improve reliability in the feed industry. However, these models predict NEL20 based on estimates, not in vivo values.

Implementation of the model could encounter challenges related to specific ingredients, such as urea content. In the NorFor system, urea has a net energy content of zero; therefore, $\mathrm{CP}$ was corrected for the $\mathrm{CP}$ originating from added urea in compound feed samples used to develop the model. If not corrected, CP would include the NPN from urea; thus, the regression factor for $\mathrm{CP}$ in the model would be underestimated. This is reflected in model I2, where the coefficient of $\mathrm{CP}$ is lower when urea was not corrected, with a higher prediction error. Nevertheless, the need for urea correction challenges the objective of this study, which was to develop a model that is independent of ingredient composition, as the urea content needs to be known for it to be corrected. European and US laws require urea content on their feed labels; therefore $\mathrm{CP}_{\text {corr }}$, could be easily obtainable. An alternative approach is to analyze for ammonium- $\mathrm{N}$ in the compound feed and use this for correction of urea-N. It is important to point out that compound feed containing urea will contain higher and erroneous predicted values if not corrected. Therefore, the use of models on samples with urea would require further analyses of the urea or ammonium content.
For developing a static model, it was central for this study to detect variables that were independent from the resource-demanding kinetic feed variables, such as nutrient degradation rates and indigestible fractions. However, this also challenges the models because the rate of degradation and digestibility of ingredients may change in the future due to new varieties, feedstuffs, studies, or technology. Such changes would modify the reference values but would not affect the parameters used in the empirical model; therefore, the changes would not be reflected in the predicted values.

Maintenance of the model's predictive performance should be done frequently. Model maintenance can be accomplished by collecting and analyzing representative compound feeds and their corresponding ingredients to calculate the reference value to be used for model recalibration. Recalibration of the static model would be required whenever the reference dynamic model is changed and updated.

\section{CONCLUSIONS}

This study developed a static empirical model for the prediction of net energy content of compound feeds in NorFor by using OMD measured by EDOM and chemical components measured directly in compound feeds. The proposed best model, model I, included CFat, $\mathrm{NDF}, \mathrm{DOM}_{\mathrm{EDOM}}$, and $\mathrm{CP}_{\text {corr }}$ as independent variables. The model was developed using 75 compound feed samples as a data set, representative of the compound feeds used in the feed industry in Scandinavia today. The model could allow estimation of net energy concentration of compound feed samples when input data for the dynamic model are lacking. However, independent evaluation is required for the proposed method to be adopted as a valuable tool in practice.

\section{ACKNOWLEDGMENTS}

The authors thank the Research Council of Norway (Oslo) for funding the project. The authors also thank Lantmännen Lantbruk (Malmö, Sweden), Vallberga Lantmän (Vallberga, Sweden), Norgesfôr AS (Oslo, Norway), Felleskjøpet Agri (Lillestrøm, Norway), Fiskå Mølle AS (Tau, Norway), DLG (Copenhagen, Denmark), and Hedegaard Agro (Nørresundby, Denmark) for contributing feed samples. The authors have not stated any conflicts of interest.

\section{REFERENCES}

Åkerlind, M., and H. Volden. 2011. Standard feed value. Pages 137139 in NorFor-The Nordic Feed Evaluation System. H. Volden, ed. Wageningen Academic Publishers. 
Allen, D. M. 1974. The relationship between variable selection and data augmentation and a method for prediction. Technometrics 16:125-127. https://doi.org/10.2307/1267500.

Álvarez, C., E. Prestløkken, N. I. Nielsen, H. Volden, G. Klemetsdal, and M. R. Weisbjerg. 2020. Precision and additivity of organic matter digestibility obtained via in vitro multi-enzymatic method. J. Dairy Sci. 103:4880-4891. https://doi.org/10.3168/jds.2019 -17778 .

Bates, D., M. Mächler, B. Bolker, and S. Walker. 2015. Fitting linear mixed-effects models using lme4. J. Stat. Softw. 67:1-48. https:// doi.org/10.18637/jss.v067.i01.

Baumont, R., D. Sauvant, G. Maxin, P. Chapoutot, G. Tran, A. Boudon, S. Lemosquet, and P. Nosiere. 2018. Calculation of feed values in INRA system: Feed tables and prediction equations. Pages 411-439 in INRA Feeding System for Ruminants. D. Sauvant, L. Delaby, and P. Nozière, ed. Wageningen Academic Publishers.

Cottyn, B. G., J. V. Aerts, J. M. Vanacker, R. J. Moermans, and F. X. Buysse. 1984. The prediction of the net energy value of compound feedstuffs for dairy cattle. Anim. Feed Sci. Technol. 11:137-147. https://doi.org/10.1016/0377-8401(84)90018-X.

Danish Veterinary and Food Administration. 2020. Officiel metodeliste til kontrol af foder. Ministeriet for fødevarer, landbrug og fiskeri. Accessed Dec. 22, 2020. https://www.foedevarestyrelsen .dk/SiteCollectionDocuments/Laboratorie/Officiel\%20metodeliste $\% 20$ til\%20kontrol\%20af\%20foder.pdf.

De Boever, J. L., B. G. Cottyn, J. M. Vanacker, and C. V. Boucqué. 1994. An improved enzymatic method by adding gammanase to determine digestibility and predict energy value of compound feeds and raw materials for cattle. Anim. Feed Sci. Technol. 47:1-18. https://doi.org/10.1016/0377-8401(94)90155-4.

Dumas, J. 1831. Procedes de l'analyse organique. Ann. Chim. Phys. 247:198-213.

European Commission. 2009. Laying down the methods of sampling and analysis for the official control of feed. Off. J. L54:1-130.

European Commission. 2010. Annex IV to Regulation (EC) No $767 / 2009$ on permitted tolerances for the compositional labelling of feed materials or compound feed as referred to in Article 11(5). Off. J. L229:1-130.

GfE. 2009. New equations for predicting metabolisable energy of compound feeds for cattle. Page 143 in Proc. Society of Nutrition Physiology. Frankfurt, Germany.

Giger-Reverdin, S., J. Aufrère, D. Sauvant, C. Demarquilly, and M. Vermorel. 1994. Prediction of the energy values of compound feeds for ruminants. Anim. Feed Sci. Technol. 48:73-98. https://doi.org/ 10.1016/0377-8401(94)90113-9.

Hansen, B. 1989. Determination of nitrogen as elementary N, an alternative to Kjeldahl. Acta Agric. Scand. 39:113-118. https://doi .org/10.1080/00015128909438504

Hurvich, C. M., and C. Tsai. 1989. Regression and time series model selection in small samples. Biometrika 76:297-307. https://doi .org/10.1093/biomet/76.2.297

ISO (International Organization for Standardization). 2006. Animal feeding stuffs - Determination of amylase-treated neutral detergent fiber content (aNDF). Standard no. 16472:2006. ISO.

Kock, N., and G. Lynn. 2012. Lateral collinearity and misleading results in variance-based SEM: An illustration and recommendations. J. Assoc. Inf. Syst. 13:546-580. https://doi.org/10.17705/ 1jais.00302.

Kristensen, N. B., A. Storm, B. M. Raun, B. A. Røjen, and D. L. Harmon. 2007. Metabolism of silage alcohol in lactating dairy cows. J. Dairy Sci. 90:1364-1377. https://doi.org/10.3168/jds.S0022 $-0302(07) 71623-5$.

Liu, K. 2019. Effect of sample size, dry ashing temperature and duration on determination of ash content in algae and other biomass. Algal Res. 40:101486. https://doi.org/10.1016/j.algal.2019.101486.
NorFor. 2020. NorFor Feed Table. Accessed Sep. 20, 2020. http://www .norfor.info/feed-table/.

Nørgaard Pedersen, E. 1962. Om aske- og sandbestemmelse i roetop. Pages 435-458 in Tidsskrift for planteavl [in Danish]. F. Olsen, ed. Statens planteavlsudvalg.

Sauvant, D., L. Delaby, and P. Nozière. 2018. INRA Feeding System for Ruminants. Wageningen Academic Publishers.

Sauvant, D., J. M. Perez, and G. Tran. 2002. Valeurs nutritives pour les ruminants. Pages $43-50$ in Tables de composition et de valeur nutritive des matières premières destinées aux animaux d'élevage (porcs, volailles, bovins, ovins, caprins, lapins, chevaux, poissons). D Sauvant, J. M. Perez, and G. Tran, ed. INRA Editions.

St-Pierre, N. R. 2003. Reassessment of biases in predicted nitrogen flows to the duodenum by NRC 2001. J. Dairy Sci. 86:344-350. https://doi.org/10.3168/jds.S0022-0302(03)73612-1.

Tedeschi, L. O., D. G. Fox, R. D. Sainz, L. G. Barioni, S. R. Medeiros, and C. Boin. 2005. Mathematical models in ruminant nutrition. Sci. Agric. 62:76-91. https://doi.org/10.1590/S0103 $-90162005000100015$.

Thomas, C. 2004. Feed into Milk: A New Applied Feeding System for Dairy Cows. Nottingham University Press.

Thomas, P. C., S. Roberston, D. G. Chamberlain, R. M. Livngstone, P. H. Garthwaite, P. J. S. Dewey, R. Smart, and C. Whyte. 1988. Predicting the metabolizable energy content of compounded feeds for ruminants. Pages 127-146 in Recent Advances in Animal Nutrition. W. Haresign and D. J. A. Cole, ed. Butterworths.

Tylutki, T. P., D. G. Fox, V. M. Durbal, L. O. Tedeschi, J. B. Russell, M. E. Van Amburgh, T. R. Overton, L. E. Chase, and A. N. Pell. 2008. Cornell Net Carbohydrate and Protein System: A model for precision feeding of dairy cattle. Anim. Feed Sci. Technol. 143:174202. https://doi.org/10.1016/j.anifeedsci.2007.05.010.

Venables, W. N., and B. D. Ripley. 2002. Modern Applied Statistics with S. 4th ed. Springer.

Volden, H. 2011. NorFor-The Nordic Feed Evaluation System. H. Volden, ed. Wageningen Academic Publishers.

Watson, M. E., and T. Galliher. 2001. Comparison of Dumas and Kjeldahl methods with automatic analyzers on agricultural samples under routine rapid analysis conditions. Commun. Soil Sci. Plant Anal. 32:2007-2019. https://doi.org/10.1081/CSS-120000265.

Weisbjerg, M. R., and T. Hvelplund. 1993. Bestemmelse af nettoenergiindhold (FEK) i råvarer og kraftfoderblandinger [in Danish]. Report no. 3. S. Husdyrbrugsfors $\varnothing \mathrm{g}$.

Weisbjerg, M. R., and T. Hvelplund. 1996. The use of enzymatic solubility for the prediction of organic matter digestibility of compounded feedstuff. Pages 99-102 in Proc. In Vitro and In Vivo Methods Used in Experiments on Digestion Processes and Feed Evaluation. The Kielanowski Institute of Animal Physiology and Nutrition, Polish Academy of Sciences.

Zuur, A. F., E. N. Ieno, and C. S. Elphick. 2010. A protocol for data exploration to avoid common statistical problems. Methods Ecol. Evol. 1:3-14. https://doi.org/10.1111/j.2041-210X.2009.00001.x.

\section{ORCIDS}

C. Álvarez @ https://orcid.org/0000-0001-7300-6831

N. I. Nielsen ๑ https://orcid.org/0000-0002-2838-0047

M. R. Weisbjerg 은 https://orcid.org/0000-0002-6514-9186

H. Volden ๑ https://orcid.org/0000-0002-5790-2086

E. Prestløkken ๑ https://orcid.org/0000-0003-3151-6782 